\title{
Characterization of the Thermo-Mechanical Behavior of Insulated Cable Stacks Representative of Accelerator Magnet Coils
}

\author{
M. Reytier, A. Devred, M. Durante, C. Gourdin, P. Védrine
}

\begin{abstract}
A key issue in the design and fabrication of superconducting accelerator magnets is the detailed knowledge of the thermo-mechanical properties of their components. Measurements have been performed on straight stacks of Rutherford-type cables representative of magnet coils. The investigated samples are made up of $\mathrm{NbTi}$ and $\mathrm{Nb}_{3} \mathrm{Sn}$ cables, insulated with quartz-fiber tapes and vacuum-impregnated with epoxy resin. The characterization includes compressive behavior studies at room and liquid helium temperatures, as well as measurements of thermal shrinkage coefficients. After a detailed description of the experimental procedures, tables of practical numbers that can be used by magnet designers are presented.
\end{abstract}

Index Terms-Measurements at Cryogenic Temperature, Rutherford-type Cables, Thermal Contraction, Young's Modulus.

\section{INTRODUCTION}

To achieve good performances, the design of superconducting accelerator magnets has to ensure that the coils are still under compressive stress after energization at liquid helium temperature. If this condition is not realized, conductor displacements could occur, leading to quenches or field quality degradation. To compensate the thermal shrinkage differentials between various cold mass components, as well as the Lorentz forces, a compressive load is applied on the coils during assembly. However, the prestress must be limited to prevent coil damage and reduce tool size. In order to optimize the design of such structures at each step (manufacturing, cooldown and excitation), finite element calculations are carried out [1]. These analyses require a good knowledge of coil mechanical behavior, including the Young's modulus at the involved temperatures as well as thermal contraction coefficients. To determine experimentally these key design parameters, specific test devices have been developed at CEA Saclay and presented elsewhere [2]. We report here on a new series of measurements performed on other constituents, associated with a refined analysis procedure.

Manuscript received September 17, 2000.

CEA Saclay, DSM/DAPNIA/STCM, 91191 Gif sur Yvette, France reytier@dapnia.cea.fr

Web page: www-dapnia.cea.fr/Phys/Stcm/nb3sn

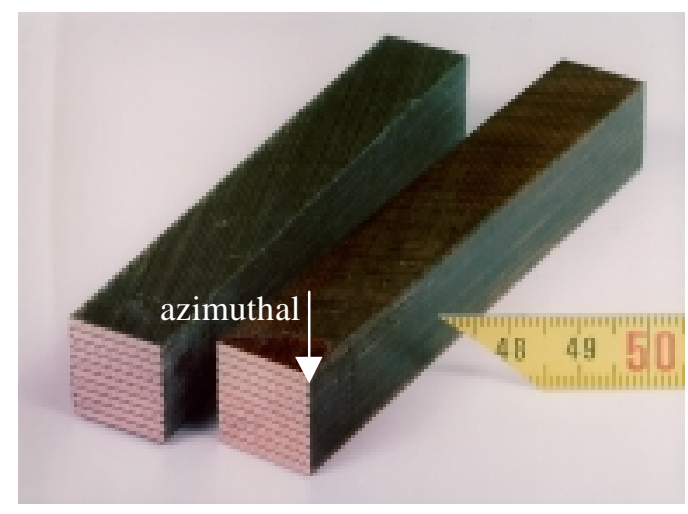

Fig. 1. Ten-Stack Samples

\section{SAMPLES DESCRIPTION}

\section{A. Cables and their Insulation}

Two sets of samples were measured, using two different cable types, but relying on the same insulation system. Salient cable parameters are summarized in Table I. The two cable types have similar geometry and are both slightly keystoned. One is made of NbTi strands and is used for the Large Hadron Collider arc quadrupole magnets [3], and the other is made of $\mathrm{Nb}_{3} \mathrm{Sn}$ strands and is developed for a quadrupole magnet model under study at CEA Saclay [4].

All samples were prepared in the same way. The cables were insulated with a $15-\mathrm{mm}$-wide, $60-\mu \mathrm{m}$-thick quartz fiber tape. The tape was first heat treated in air at $350{ }^{\circ} \mathrm{C}$ during 15 hours, to remove all organic binders, and then wrapped around the cables. The wrapping was made up of two layers without overlap. Stacks of ten insulated cables were manufactured. The stacking was alternated from layer to layer to compensate the cable keystone. In the case of $\mathrm{Nb}_{3} \mathrm{Sn}$, the ten-stack samples were submitted to a heat treatment at $660{ }^{\circ} \mathrm{C}$ during 120 hours in a flow of pure argon gas, to simulate the heat treatment required for $\mathrm{Nb}_{3} \mathrm{Sn}$ compound formation according to the internal tin process. Finally, all $\mathrm{NbTi}$ and $\mathrm{Nb}_{3} \mathrm{Sn}$ insulated samples were vacuumimpregnated with epoxy resin (MY745 resin, HY905 hardener, DY072 and DY073 catalysts from Ciba [5], [6]) and cured for 12 hours at $95{ }^{\circ} \mathrm{C}$ followed by 48 hours at $110^{\circ} \mathrm{C}$. The stack heights and widths were controlled during heat treatment and impregnation, thanks to carefully dimensioned molds. 
TABLE I

SALIENT CABLE PARAMETERS

\begin{tabular}{ccc}
\hline \hline & Nh $_{3}$ Sn Cahle $^{\mathbf{a}}$ & NhTi Cahle $^{\mathbf{b}}$ \\
Strand Diameter & 0.825 & 0.825 \\
Number of Strands & 36 & 36 \\
Cable Width (mm) & 15.1 & 15.1 \\
Mid-Thickness (mm) & 1.485 & $1.480 \pm 0.006$ \\
Keystone angle & $0.94^{\circ}$ & $0.90 \pm 0.05^{\circ}$ \\
Cable Twist (mm) & 101 & $100 \pm 5 \mathrm{~mm}$ \\
& $\begin{array}{c}\text { 316 L core between the two } \\
\text { strand layers of each cable }\end{array}$ \\
\hline \hline
\end{tabular}

${ }^{\mathrm{a}}$ Manufacturor measurements.

\section{B. Other Samples}

Other samples only made of epoxy resin were also manufactured in the same mold and with the same process. Moreover, reference metallic samples were used. They consist of C70250 copper, 6060 T5 aluminum alloy, ASTM B348/Grade2 titanium and 304L stainless steel bars, with dimensions closed to the ten-stack ones (17 mm high, $15 \mathrm{~mm}$ wide and $100 \mathrm{~mm}$ long).

\section{YounG's Modulus MEASUREMENTS}

\section{A. Experimental Procedure}

The stress-strain curve of each sample was monitored for three successive cycles at room temperature and in saturated helium I at $4.2 \mathrm{~K}$. As illustrated in Fig. 2, each sample was mounted in the groove of a stainless steel mold and was loaded in compression along its azimutal direction through a stainless steel upper bar.

The displacement was measured between a reference surface tied to the bottom part of the mold and the lower surface of the upper bar. The displacement measurements were performed using two HBM sensors (see Fig. 2), which rely on a strain gage technique, and whose signals have been calibrated at both measurement temperatures. The load was applied at a constant crosshead displacement speed of $0.2 \mathrm{~mm} / \mathrm{min}$ by an INSTRON tensile machine, with a calibrated $150 \mathrm{kN}$ load cell. The experimental procedure included three successive cycles between $2.5 \mathrm{kN}$ and $150 \mathrm{kN}$. The displacement sensors were reset to zero under a load of $2.5 \mathrm{kN}$ at the beginning of each sample test at each temperature. The $2.5 \mathrm{kN}$ were deemed necessary to compensate small geometric defects of the samples.

The first step was to evaluate the mold rigidity. This was done using the reference aluminum alloy bar, whose Young's modulus was assumed to be known (see Table III). Subsequently, the raw data were all corrected by taking into account this rigidity. Next, we tested the other metallic bars in order to validate the experimental method by comparing our results with published data (see Tables II and III). Finally, we tested the two types of ten-stack samples. The elastic modulus given below corresponds to the slope of a linear regression of the stress-strain data, only based on the last loading of the three cycles.

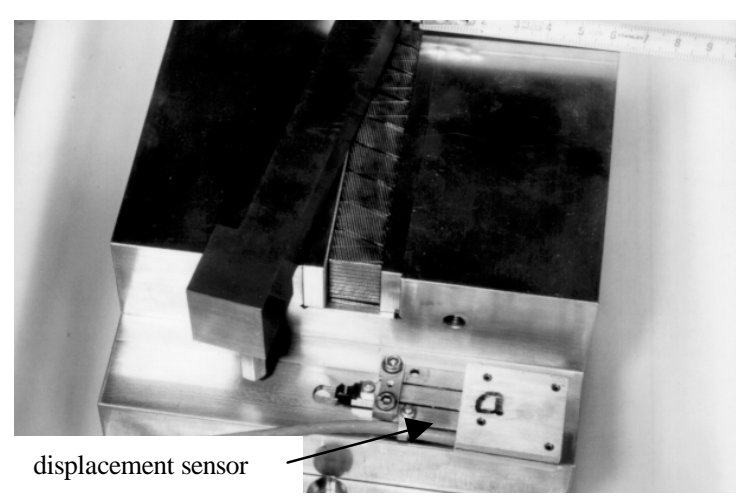

Fig. 2. Compression mold

\section{B. Results and Analyses}

For all $\mathrm{Nb}_{3} \mathrm{Sn}$ samples, the first loading on a virgin stack is very different from the subsequent ones, and from the ones observed on NbTi samples (Figs. 3a and 3b). The curve exhibits a slow start, followed by a pronounced non-linear behavior, whose average slope is smaller than the slopes of the following loadings. Furthermore, the curve appears to exhibit an hysteresis between loading and unloading. The hysteresis evolves from cycle to cycle and seems to be more or less stabilized after three loadings. In addition, the test temperature has a marked effect on the $\mathrm{Nb}_{3} \mathrm{Sn}$ stack behavior. The main differences between $293 \mathrm{~K}$ and $4.2 \mathrm{~K}$ are: an increase of the elastic modulus associated with a reduction of the hysteresis cycle. This significant thermal dependence of the elastic properties has to be taken into account in the design calculations [1].

Similarly, the first loading of the virgin NbTi samples also appears to be different from the subsequent ones, but its shape does not present the strong non-linearity observed on the $\mathrm{Nb}_{3} \mathrm{Sn}$ samples. The curves also exhibit an hysteresis between loading and unloading, of the same order of magnitude as for $\mathrm{Nb}_{3} \mathrm{Sn}$ samples. Moreover, an increase of the Young's modulus and a reduction of the hysteresis can be noticed at $4.2 \mathrm{~K}$.

Finally, compared with previous ten-stack samples made up of $\mathrm{NbTi}$ cables with polyimide insulation [2], the compressive behavior of the impregnated NbTi stacks is much more rigid. Their elastic modulus is also very close to the $\mathrm{Nb}_{3} \mathrm{Sn}$ values, as summarized in Table II. Therefore, the insulation system seems to play a great role in the azimutal compressive behavior of cable stacks, while the very first loading is not yet understood. Irregular strand positioning, observed on sample cross-sections, leads us to interpret the strong non-linear behavior of virgin $\mathrm{Nb}_{3} \mathrm{Sn}$ stacks as a rearrangement of strands. However, this hypothesis has to be confirmed by more refined optical observations.

Average elastic modulus for each sample set is summarized in Table II. The Young's modulus of reference metallic bars is in good agreement with the literature [7]. Given the measurement errors, it can be seen that our experimental setup is more appropriate to the measurements of low modulii than of high ones, and is suited to cable stacks. 
TABLE II

YOUNG'S MODULUS (GPa)

\begin{tabular}{ccccc}
\hline \hline Sample & $\begin{array}{c}\text { Number } \\
\text { of Tests }\end{array}$ & $293 \mathrm{~K}$ & $\begin{array}{c}\text { Number } \\
\text { of Tests }\end{array}$ & $4.2 \mathrm{~K}$ \\
\hline Copper & 3 & $130 \pm 5$ & & \\
Titanium & 3 & $115 \pm 1$ & & \\
S. Steel & 5 & $220 \pm 20$ & & $8.6 \pm 0.2$ \\
& & & & $45 \pm 1$ \\
Resin & 5 & $4.2 \pm 0.2$ & 2 & $46 \pm 1$ \\
Nb3Sn stacks & 6 & $33 \pm 1$ & 2 & 2 \\
NbTi stacks & 2 & $32 \pm 1$ & 2 &
\end{tabular}
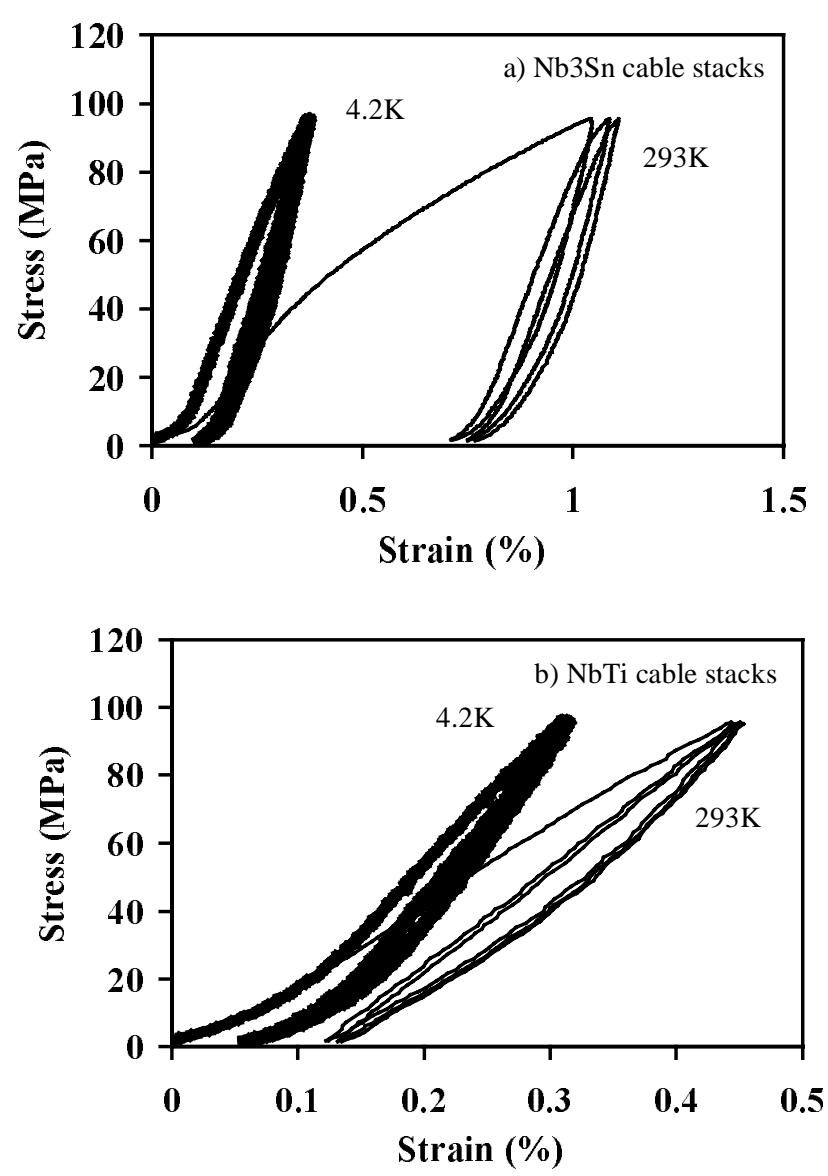

Fig. 3. Compressive behavior of conductor stacks: (a) $\mathrm{Nb}_{3} \mathrm{Sn}$ samples and (b) NbTi samples.

\section{Thermal Shrinkage MEASUREMENTS}

\section{A. Experimental Procedure}

Previous works described thermo-mechanical measurements of coil properties, thanks to strain gages glued on the sample [8], [9], or thanks to dilatometers [10]. Here, the thermal shrinkage coefficient is determined, based on the knowledge of the elastic modulus at the involved temperatures, associated with a force measurement [11].

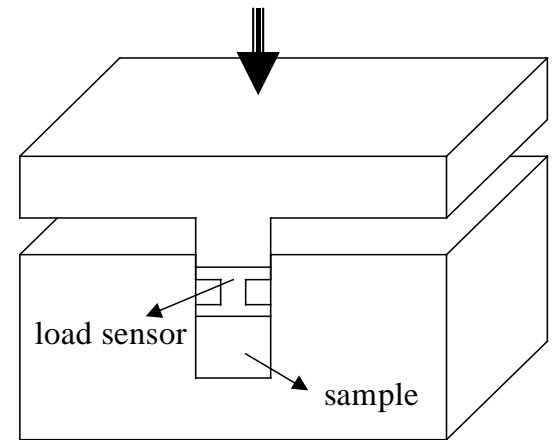

Fig. 4 : Thermal contraction measurement device

The sample is mounted in a specific, U-shaped, stainless steel mold, closed by a bolted, T-shaped upper plate designed to apply a given compressive load, as shown in Fig. 4. Once the desired compressive stress is achieved at room temperature, the whole fixture is cooled down to liquid helium temperature (4.2 K).

The compressive force evolution is monitored throughout the experiment by a specific force sensor inserted between the sample and the T-shaped plate. It is made up of a stainless steel I beam, equipped with four half-bridges of strain gages, located on both sides of the beam, at $1 / 4$ and $3 / 4$ of the length. The calibration of the strain gages signals at room temperature and in liquid helium at $4.2 \mathrm{~K}$ has been described in details elsewhere [2].

\section{B. Principle of Measurement Analysis}

In our test setup, the integrated thermal shrinkage coefficient between room and liquid helium temperature can be written in the following way by using the linear thermoelasticity formulation [11]:

$$
\int_{293 \mathrm{~K}}^{4 \mathrm{~K}} \alpha_{\text {sample }} \cdot \mathrm{dT}=\int_{293 \mathrm{~K}}^{4 \mathrm{~K}} \alpha_{\text {mold }} \cdot \mathrm{dT}+\frac{F_{293 \mathrm{~K}}}{E_{293 \mathrm{~K}} \cdot \mathrm{S}}-\frac{F_{4 \mathrm{~K}}}{E_{4 \mathrm{~K}} \cdot \mathrm{S}}-\frac{F_{4 \mathrm{~K}}-F_{293 \mathrm{~K}}}{K_{\text {mold }}}
$$

where $S$ is the initial, pressed area, $E_{\mathrm{T}_{\mathrm{i}}}$ is the sample elastic modulus at temperature $T_{\mathrm{i}}$ (see below), $F_{\mathrm{T}_{\mathrm{i}}}$ is the applied force measured by the I-beam sensor, $K_{\text {mold }}$ is the mold rigidity, and $\alpha_{\text {sample }}$ and $\alpha_{\text {mold }}$ are the thermal expansion coefficients.

The above equation is derived assuming an elastic behavior ( $E_{\mathrm{T}_{\mathrm{i}}}$ independent of stress), and small deformations hypothesis ( $S$ constant). In practice, the elastic modulus of stack samples used in Eq. (1) is determined from the last unloading branch of the stress-strain curves described above at the given temperature. For each sample, we verified that $F_{\mathrm{T}_{\mathrm{i}}}$ was in the data range used for $E_{\mathrm{T}_{\mathrm{i}}}$ determination.

In order to identify $\alpha_{\text {mold }}$ and $K_{\text {mold }}$, reference titanium and aluminum bars were used with the assumed characteristics given in Table III. The other reference metallic bars were also tested to validate the experimental procedure by a crosscheck with published data. 
TABLE III

DATA USED IN ANALYSES

\begin{tabular}{cc}
\hline \hline Sample & From [7] \\
\hline \multirow{2}{*}{ Titanium } & $E_{293 \mathrm{~K}}=115 \mathrm{GPa}$ \\
& $E_{4 \mathrm{~K}}=131 \mathrm{GPa}$ \\
$\mathcal{E}_{293 \mathrm{~K}-4 \mathrm{~K}}=-1.51 \mathrm{~mm} / \mathrm{m}^{\mathrm{a}}$ \\
\hline \multirow{3}{*}{ Aluminum alloy } & $E_{293 \mathrm{~K}}=70 \mathrm{GPa}$ \\
& $E_{4 \mathrm{~K}}=80 \mathrm{GPa}$ \\
\hline Copper & $\varepsilon_{293 \mathrm{~K}-4 \mathrm{~K}}=-4.19 \mathrm{~mm} / \mathrm{m}^{\mathrm{a}}$ \\
\hline Stainless Steel & $E_{293 \mathrm{~K}}=128 \mathrm{GPa}$ \\
& $E_{4 \mathrm{~K}}=139 \mathrm{GPa}$ \\
\hline \hline antegrated thermal shrinkage coefficient between $293 \mathrm{~K}$ and $4.2 \mathrm{~K}$
\end{tabular}

${ }^{\mathrm{a}}$ Integrated thermal shrinkage coefficient between $293 \mathrm{~K}$ and $4.2 \mathrm{~K}$.

\section{Results}

The mold integrated thermal coefficient, determined from the measurements of reference aluminum and titanium bars, is $-3.1 \mathrm{~mm} / \mathrm{m}$, and is consistent with stainless steel [7]. Furthermore, the values obtained for the other reference metallic samples (copper and stainless steel) are also in a quite good agreement with published data and, therefore, validate the experimental procedure.

Table IV presents a summary of the measured integrated thermal shrinkage coefficients compared to the literature. Once more, it can be noticed that the two types of cable stack present similar thermal shrinkage coefficients, but that these values differ from the polyimide-insulated $\mathrm{NbTi}$ stack coefficient measured previously [2]. Therefore, the thermal shrinkage of ten-stack samples seems to be more dependent on insulation system than on cable type.

TABLE IV

INTEGRATED THERMAL SHRINKAGE COEFFICIENT BETWEEN $293 \mathrm{~K}$ AND $4.2 \mathrm{~K}$

\begin{tabular}{cccc}
\hline \hline Sample & $\begin{array}{c}\text { Number } \\
\text { of Tests }\end{array}$ & $\begin{array}{c}\text { Test Result } \\
(\mathrm{mm} / \mathrm{m})\end{array}$ & $\begin{array}{c}\text { Literature } \\
(\mathrm{mm} / \mathrm{m})\end{array}$ \\
\hline Copper & 1 & -3.4 & $-3.24[7]$ \\
\hline S. Steel & 1 & -2.9 & $-3.06[7]$ \\
\hline Resin & 2 & $-18.8 \pm 0.1$ & $\begin{array}{c}-11.6[7] \\
\text { up to }-14[12]\end{array}$ \\
\hline $\mathrm{Nb}_{3}$ Sn Stacks & 2 & $-3.9 \pm 0.1$ & $-3.50[9]$ \\
$-3.30[8]$
\end{tabular}

\section{CONCLUSION}

Insulated $\mathrm{Nb}_{3} \mathrm{Sn}$ and $\mathrm{NbTi}$ cable stacks were manufactured in order to determine their thermo-mechanical properties as needed for accelerator magnet design. The experimental methods were validated, thanks to reference metallic samples. Practical numbers were given and the role of the insulation system was emphasized. Now, efforts in the understanding of the involved mechanisms have to be made in order to develop a suitable behavior model.

\section{ACKNOWLEDGMENTS}

The authors wish to thank the technical staff of DAPNIA/STCM involved in the tests, and more particularly S. Cazaux, C. Génin, and G. Lemierre.

\section{REFERENCES}

[1] C. Gourdin, A. Devred, M. Durante, "Mechanical design of a $\mathrm{Nb}_{3} \mathrm{Sn}$ quadrupole magnet," Presented at EPAC2000, Vienna, Austria, 2000.

[2] P. Vedrine, B. Gallet, C. Nouvel, "Measurement of thermo-mechanical properties of NbTi windings for accelerator magnet," IEEE Trans. Appl. Supercond., Vol. 9 No. 2, pp. 236-239, June 1999.

[3] M. Peyrot, J.M. Rifflet, F. Simon, P. Vedrine, T. Tortschanoff, "Construction of the new prototype of main quadrupole cold masses for the arc short straight sections of LHC," IEEE Trans. Appl. Supercond., Vol. 10 No. 1, pp. 170-173, March 2000.

[4] A. Devred, M. Durante, C. Gourdin, F.P. Juster, M. Peyrot, J.M. Rifflet, F. Streiff, P. Vedrine, "Development of a $\mathrm{Nb}_{3} \mathrm{Sn}$ quadrupole magnet model," in these Proceedings.

[5] J.M. Rey, B. Gallet, "Epoxy resin developments for large superconducting magnets impregnation," Cryogenics, Vol. 38, pp. 19-23, 1998.

[6] Ciba Specialty Chemicals Inc., Klybeckstrasse 141, CH-4002 Basel.

[7] R.P. Reed, A.F. Clark, Materials at Low Temperature, Metals Park, OH: ASTM, 1983.

[8] C.A. Swenson, I.R. Dixon, W.D. Markiewicz, "Measurement of thermal contraction properties for NbTi and Nb3Sn Composites," IEEE Trans. Appl. Supercond., Vol. 7 No. 2, pp. 408-411, June 1997.

[9] D.R. Chichili, T.T. Arkan, J. P. Ozelis, I. Terechkine, "Investigation of cable insulation and thermo-mechanical properties of $\mathrm{Nb}_{3} \mathrm{Sn}$ composite," IEEE Trans. Appl. Supercond., Vol. 10 No. 1, pp. 1317-1320, 2000.

[10] S.S. Kozub, V.V. Zubko, "Mechanical and thermal properties of structural materials and coil of UNK superconducting magnet," Proc. of $15^{\text {th }}$ International Conference on Magnet Technology, Beijing: Science Press, pp. 1186-1189, 1998.

[11] J. Lemaitre, J.L. Chaboche, Mechanics of Solid Materials, Cambridge University Press, 1990.

[12] G. Hartwig, "Thermal expansion of fibre composites," Cryogenics, vol. 28, pp.255-266, April 1988. 